\title{
Development of Directionally Oriented Compressive Weft Knitted Fabrics
}

\section{Cruz $\mathbf{J}^{*}$, Sampaio $\mathbf{S}$ and Fangueiro $\mathbf{R}$}

Centre for Textile Science and Technology, University of Minho, Portugal

\begin{abstract}
Polyamide/elastane knitted fabrics with directionally oriented compressive ability was studied. Knitting designs with coursewise, diagonal, walewise, and both coursewise and walewise compressive orientations were created and analysed at four different angles $\left(0^{\circ},+45^{\circ},-45^{\circ}\right.$ and $\left.90^{\circ}\right)$ and up to $50 \%$ elongation. At the same stretching and same direction (angle), the tensile force was higher for samples from Serie B (only the elastane was producing miss stitches) than for samples from Serie A (polyamide and elastane yarns were simultaneously producing miss stitches), in most of the cases. There are higher differences between tensile force values of samples from Serie $B$ with the different number of miss stitches, however, very little difference in tensile force values is seen between samples from Serie A with the different number of miss stitches, in most of the cases. Also the tensile force is the highest when samples from Serie B with walewise compressive orientation are stretched at $90^{\circ}$ direction, the tensile force value was two times and half higher than that of the same compressive orientation but from Serie $A$. At $0^{\circ}$ direction, the force values of the samples with coursewise compressive orientation from Serie A were higher than that of samples from Serie B due to miss loops force orientation. At the $+45^{\circ}$ and $-45^{\circ}$ directions, the force values of the two Series are similar, showing that the designs and the yarns used are less important due to force orientation. Fabrics with diagonal compressive orientation have force values similar among each sample, in all four directions, the diagonal structure enables the control of fabric anisotropy. The prediction of force values in relation to the number of miss stitches sequences and in relation to the different angles are made using regression model. This analysis helps engineer compressive devices with adjustable and directionally oriented stretch structures.
\end{abstract}

Keywords: Elastic behaviour; Directionally oriented compression; Knitted fabrics

\section{Introduction}

The main application of compression garment is for treating venous insufficiency, for example, treatment of varicose veins. However, it presents many other applications such as for treating burns, fatigue, dislocations, muscle fatigue, sprains and low blood pressure. It is also used and recommended for long flights to avoid the occurrence of deep vein thrombosis and postpartum recovery [1,2].

Moreover, since no body part is a uniform cylinder, pressure exerted by a garment with a given tension is not uniform and is distributed differently over the various areas of the body for any given person. Clearly concave areas of the body do not make contact with the pressure garment and therefore no pressure is exerted on them [3].

The level of compression is governed by the garment size as well as the amount of fabric stretching. Fabrics used for compression garments are usually engineered with stretchable structure and containing elastomeric material to achieve highly stretchable appropriate compression [4].

In today's athletics environment, many athletes wear compression garments. Elastic garments for sports and outer wear play an important role in optimizing an athletic performance by providing freedom movement, minimizing the risk of injury or muscle fatigue, and reducing friction between body and garment. In the absence of body motion, many garments provide apparent comfort. However the moment the physical movement is made, the comfort performance level changes, and that change could be significant. During movement, different parts of the body stretch very differently, and the amount of stretch will vary differently in each direction [5].

However, most compression garments do not provide targeted support to specific body areas, but rather overall compression. As a result, compression garments have inherent unwanted push-pull effects that reduce the garment ability to maintain optimal compression support for complex moving muscles. Some compression garments provide specific targeted higher compression zones by sewing particular compression fabric panels in dedicated areas and adjoining the panel shapes at the seams. However, the amount of targeted support zones is always limited due to the practical construction complications that will always arise from sewing too many seam lines in the garment. In addition, an abundance of seams naturally leads to a higher propensity towards the possibility of skin chaffing for the wearer, regardless even if the seams are flat-locked [6].

Single or double covered elastomers with different stretch moduli and linear densities are usually used in knitted fabrics to achieve specific stretch and pressure scales. The degree of stretch and recovery of knitted fabrics depends on the amount of elastic material incorporated and on the stitch construction of the fabrics $[7,8]$. The understanding on how to optimise the stretch potential in pattern design is, in relative terms, still in its infancy. Comprehensive study detailing all aspects of an objective approach to stretch pattern development has not been done so far [9]. Furthermore, the possibility to design knitted fabrics with directionally oriented compressive ability is also not yet been done.

The objective is to find ways of improving the compressive properties of knitted fabrics at different fabric orientations by the engineering design of structures (pattern designs). Various authors [10-12] stated that the tensile behaviour of knitted fabrics are directly derived from

*Corresponding author: Cruz J, Centre for Textile Science and Technology, University of Minho, Portugal, Tel: 351253510204; E-mail: julianacruz@det.uminho.pt. Received February 29, 2016; Accepted April 04, 2016; Published April 11, 2016 Citation: Cruz J, Sampaio S, Fangueiro R (2016) Development of Directionally Oriented Compressive Weft Knitted Fabrics. J Textile Sci Eng 6: 247. doi:10.4172/2165-8064.1000247

Copyright: (c) 2016 Cruz J, et al. This is an open-access article distributed under the terms of the Creative Commons Attribution License, which permits unrestricted use, distribution, and reproduction in any medium, provided the original author and source are credited. 
the loop configuration and the yarn properties. However, these analysis were mostly limited to knitted fabrics subjected to biaxial (coursewise and walewise) stresses. The coursewise compressive orientation is expected to be manily influenced by the yarn properties and the diagonal, walewise, and both coursewise and walewise compressive orientations, is expected to be mainly influenced by the knitted pattern. Based on these assumptions, in this paper, different knitted fabrics were developed with coursewise, diagonal, walewise and both coursewise and walewise compressive orientations based on their pattern designs. The influence of different structural designs on the elastic behaviour of knitted fabrics composed by elastane and polyamide yarns have been thoroughly investigated and discussed. Different knitting designs have been created and analysed at four different angles $\left(0^{\circ},+45^{\circ},-45^{\circ}\right.$ and $90^{\circ}$ ). Furthermore, the impact of the knitting yarn and the number of miss loops on knitted fabrics elastic behaviour was also studied for all the samples at the four different angles selected.

\section{Materials and Methods}

Polyamide and elastane knitted fabrics have been produced for investigating the elastic behavior affected by varying the number and position of miss loops. Polyamide 6.6 yarn produced with $44 \mathrm{dtex}$ linear density, with 34 filaments (PA 44/34), and elastane yarn produced in a conventional double covering machine with linear density of elastane core of 156 dtex, with polyamide 6.6 double cover 78 dtex with 23 filaments (EA 156 D PA78/23) were used.

24 fabric samples were produced on a circular knitting machine with 13 inches cylinder and E24 gauge. Half of the samples were prepared from knitted constructions where the polyamide and the elastane yarns were simultaneously producing miss stitches, designated by Serie A, and the remaining half samples solely comprised constructions where only the elastane yarn was producing miss stitches, designated by Serie B.

By varying the number and the position of the miss loops different structural designs were engineered with predictable orientations in order to provide compression in that directions. Coursewise, diagonal, walewise and both coursewise and walewise orientations were created. The directionally oriented compressive knitted fabrics (DOCKFs) produced were classified into four groups:

- DOCKF_C fabrics with coursewise orientation - produced from miss stitches sequences on adjacent needles ( 1 to 3 successive miss loops) on same course (samples: 1A, 1B, 2A, $2 \mathrm{~B}, 3 \mathrm{~A}$ and $3 \mathrm{~B})$;

- DOCKF_D fabrics with diagonal orientation $\left(-45^{\circ}\right)$ - produced from miss stitch sequences on adjacent needles with one needle space ( 1 to 3 miss stitches) (samples: $4 \mathrm{~A}, 4 \mathrm{~B}, 5 \mathrm{~A}, 5 \mathrm{~B}, 6 \mathrm{~A}$ and $6 \mathrm{~B})$;

- (3) DOCKF_W fabrics with walewise orientation - produced from the effect of the miss stitches sequences on the same needle (1 to 3 successive miss loops) (samples: 7A, 7B, 8A, 8B, $9 \mathrm{~A}$ and $9 \mathrm{~B})$;

- (4) DOCKF_C \&W fabrics with both coursewise and walewise orientations, produced from miss stitches sequences on the same course and miss stiches sequences on the same wale (samples: 10A, 10B, 11A, 11B, 12A and 12B).

Their corresponding loop configurations are illustrated in Figure 1 and as can be seen in Figure 1 structure $1 \mathrm{~A}$ is the same as $7 \mathrm{~A}, 1 \mathrm{~B}$ and $7 \mathrm{~B}$ are the same, $4 \mathrm{~A}$ and $10 \mathrm{~A}$ are the same and $4 \mathrm{~B}$ and $10 \mathrm{~B}$ are also the same, and this is due to the groups' choice that was done for this research. Table 1 shows the dimensional properties of the 24 DOCKFs produced.

To investigate the impact of the different structural designs on the elastic behaviour of DOCKFs, tests were carried out according to NP EN ISO 13934 standard. The fabrics elastic behaviour were evaluated in a Hounsfield H10KS-UTM universal testing machine, at $100 \mathrm{~mm} /$ min crosshead speed using $10 \mathrm{~cm}$ gauge length, in four directions: $0^{\circ}$, $+45^{\circ},-45^{\circ}$ and $90^{\circ}$ directions of the DOCKFs specimens (Figure 2). Strip specimens were stretched up to 50\% elongation and force and elongation were recorded and averaged for the 24 samples. These fabrics were dry relaxed before mechanical testing in lab conditioning at $22^{\circ} \mathrm{C}$ and $65 \%$ RH for more than 24 hours. Such extension percentages are chosen as simple body movements stretch the knitted garment by up to $50 \%[13]$.

\section{Results and Discussion}

\section{Load capacity of DOCKFs up to $50 \%$ elongation}

Fabrics used for compression garments are usually engineered to achieve highly stretchable appropriate compression (pressure exerted by a garment with a given tension) [4]. Inlay yarn and laid-in stitches are the key knitting elements in the fabrication of compression textiles, and play a critically important role in managing and controlling high pressure magnitudes [9]. A need still exists for an effective prevention and treatment device that provides mild stretchable compression on different directions (simultaneously at different parts of the body), while, at the same time, provides comfort and wearability all day long. Therefore, in this study, the use of polyamide/elastane structures which contain miss and normal loops were chosen to produce knitted fabrics with directionally oriented mild stretchable compression. The tensile force of the elastic DOCKFs up to 50\% extension has been studied and the results are presented in Table 2, Figures 3-5.

Table 2 displays the tensile strength of the different group samples for each angle at $50 \%$ extension. Figure 3 shows the force-extension curves of the four different group samples up to $50 \%$ extension. Figure 4 shows the correlations among samples DOCKF_C, DOCKF_D, DOCKF_W and DOCKF_C\&W for force in relation to the number of miss stitches at 50\% elongation; Figure 5 shows the correlations among samples DOCKF_C, DOCKF_D, DOCKF_W and DOCKF_C \&W for force in relation to the different angles (directions) used for the tensile tests at $50 \%$ extension.

Figures 4 and 5 just include results with values of the Pearson correlation coefficient $\left(\mathrm{R}^{2}\right)$ higher than 0,80 (strongly correlated) [14].

\section{Influence of knitting yarns and number of miss stitches sequences on the stretch behaviour}

The knitting designs and the yarns used can be adjusted to provide the correct level of surface pressure in specific parts of the body. Through selection of the knitting yarns and the stitch used, 24 samples with directionally orientated compressive ability were developed. DOCKFs where the polyamide and the elastane yarns were simultaneously producing miss stitches, designated by Serie A, and the DOCKFs where only the elastane yarn was producing miss stitches, designated by Serie B, were compared.

Tensile test results are given in Table 2 and compressive forceextension curves are shown in Figure 3. Figure 3 presents typical loadextension characteristic curves for weft knitted fabrics [15]. The tensile test results of Figure 3 reveal a two stage deformation process, at the 


\begin{tabular}{|c|c|c|c|c|c|c|c|}
\hline \multicolumn{2}{|c|}{ DOCKF_C } & \multicolumn{2}{|c|}{ DOCKF_D } & \multicolumn{2}{|c|}{ DOCKF_W } & \multicolumn{2}{|c|}{ DOCKF_C\&W } \\
\hline 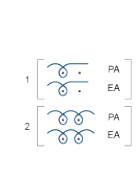 & 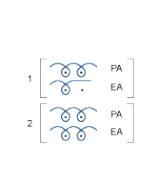 & 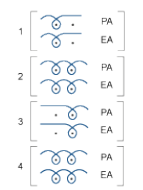 & 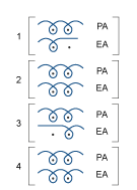 & 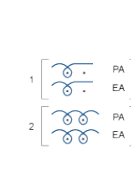 & 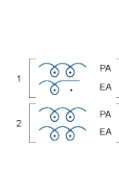 & 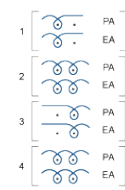 & 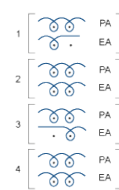 \\
\hline $\mathbf{1 A}$ & 1B & $\mathbf{4 A}$ & 4B & $7 \mathrm{~A}$ & 7B & 10A & 10B \\
\hline 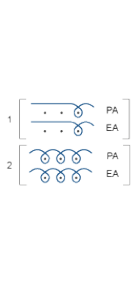 & 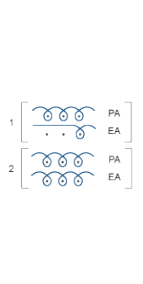 & 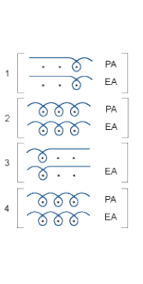 & 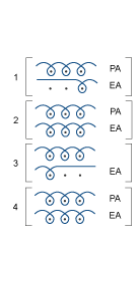 & 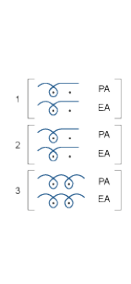 & 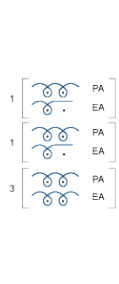 & 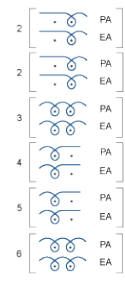 & 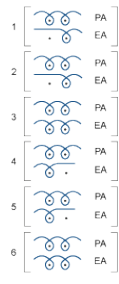 \\
\hline $2 A$ & 2B & $5 \mathbf{5 A}$ & 5B & $8 \mathbf{A}$ & 8B & $11 \mathrm{~A}$ & 11B \\
\hline 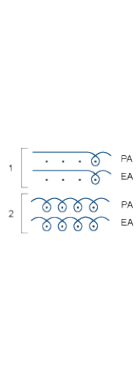 & 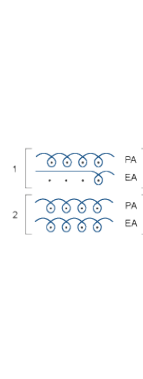 & 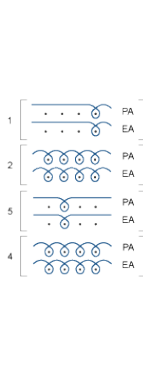 & 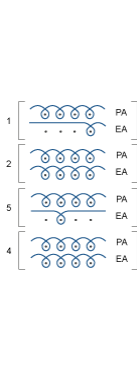 & 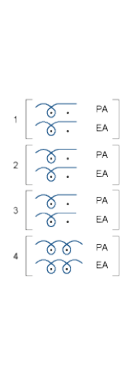 & 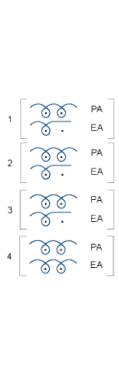 & 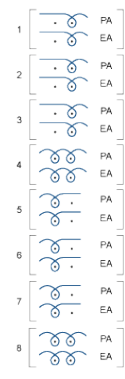 & 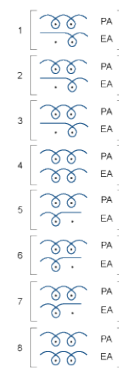 \\
\hline $\mathbf{3 A}$ & 3B & 6A & 6B & 9A & 9B & $12 \mathrm{~A}$ & 12B \\
\hline
\end{tabular}

Figure 1: Schematic diagram of different designed knitted fabrics.

\begin{tabular}{|c|c|c|c|c|c|c|c|}
\hline \multirow{2}{*}{\multicolumn{2}{|c|}{ Samples }} & \multicolumn{2}{|c|}{ Loop length (mm) } & \multirow{3}{*}{$\begin{array}{c}\text { Wales/cm } \\
15\end{array}$} & \multirow{3}{*}{$\begin{array}{c}\text { Courses/cm } \\
30\end{array}$} & \multirow{3}{*}{$\begin{array}{c}\text { Thickness (mm) } \\
1.7 \pm 0.1\end{array}$} & \multirow{3}{*}{$\begin{array}{c}\text { Aerial mass }\left(\mathrm{g} / \mathrm{m}^{2}\right) \\
489 \pm 9\end{array}$} \\
\hline & & \multirow{2}{*}{$\begin{array}{l}\text { PA } \\
2.9\end{array}$} & \multirow{2}{*}{$\begin{array}{l}\text { EA } \\
2.5\end{array}$} & & & & \\
\hline \multirow{6}{*}{ DOCKF_C } & $1 \mathrm{~A}$ & & & & & & \\
\hline & $1 \mathrm{~B}$ & 3.1 & 2.5 & 13 & 25 & $1.4 \pm 0.0$ & $376 \pm 2$ \\
\hline & $2 \mathrm{~A}$ & 3.3 & 2.9 & 13 & 25 & $1.3 \pm 0.1$ & $365 \pm 4$ \\
\hline & $2 \mathrm{~B}$ & 3.0 & 2.5 & 15 & 30 & $2.2 \pm 0.1$ & $484 \pm 2$ \\
\hline & $3 \mathrm{~A}$ & 3.0 & 3.1 & 13 & 24 & $1.1 \pm 0.1$ & $370 \pm 8$ \\
\hline & 3B & 2.7 & 2.6 & 18 & 20 & $2.3 \pm 0.2$ & $606 \pm 5$ \\
\hline \multirow{6}{*}{ DOCKF_D } & $4 \mathrm{~A}$ & 2.9 & 3.1 & 13 & 26 & $1.3 \pm 0.0$ & $385 \pm 1$ \\
\hline & $4 \mathrm{~B}$ & 2.6 & 3.0 & 13 & 24 & $1.6 \pm 0.0$ & $483 \pm 6$ \\
\hline & $5 \mathrm{~A}$ & 2.7 & 2.8 & 13 & 26 & $1.6 \pm 0.0$ & $380 \pm 4$ \\
\hline & $5 B$ & 2.8 & 2.6 & 14 & 20 & $2.0 \pm 0.1$ & $556 \pm 9$ \\
\hline & $6 \mathrm{~A}$ & 2.9 & 3.2 & 13 & 26 & $1.4 \pm 0.1$ & $460 \pm 9$ \\
\hline & $6 \mathrm{~B}$ & 3.2 & 2.8 & 13 & 25 & $1.9 \pm 0.1$ & $455 \pm 4$ \\
\hline \multirow{6}{*}{ DOCKF_W } & $7 \mathrm{~A}$ & 3.1 & 2.5 & 13 & 25 & $1.4 \pm 0.0$ & $376 \pm 2$ \\
\hline & 7B & 2.9 & 2.5 & 15 & 30 & $1.7 \pm 0.1$ & $489 \pm 9$ \\
\hline & $8 \mathrm{~A}$ & 2.7 & 3.2 & 13 & 24 & $1.3 \pm 0.0$ & $361 \pm 5$ \\
\hline & $8 \mathrm{~B}$ & 2.7 & 2.3 & 15 & 28 & $2.0 \pm 0.1$ & $492 \pm 1$ \\
\hline & $9 \mathrm{~A}$ & 2.8 & 2.8 & 13 & 26 & $1.3 \pm 0.1$ & $355 \pm 1$ \\
\hline & $9 B$ & 2.3 & 2.2 & 15 & 27 & $2.0 \pm 0.1$ & $537 \pm 3$ \\
\hline \multirow{6}{*}{ DOCKF_C\&W } & $10 \mathrm{~A}$ & 2.9 & 3.1 & 13 & 26 & $1.3 \pm 0.0$ & $385 \pm 1$ \\
\hline & $10 \mathrm{~B}$ & 2.6 & 3.0 & 13 & 24 & $1.6 \pm 0.0$ & $483 \pm 6$ \\
\hline & $11 \mathrm{~A}$ & 2.7 & 3.2 & 13 & 26 & $1.4 \pm 0.1$ & $395 \pm 2$ \\
\hline & 11B & 2.7 & 2.6 & 13 & 25 & $1.9 \pm 0.1$ & $495 \pm 9$ \\
\hline & $12 \mathrm{~A}$ & 2.6 & 3.0 & 13 & 25 & $1.3 \pm 0.1$ & $393 \pm 1$ \\
\hline & 12B & 2.8 & 3.1 & 15 & 26 & $2.1 \pm 0.2$ & $529 \pm 9$ \\
\hline
\end{tabular}

Table 1: Dimensional properties of the DOCKFs used in the study. 


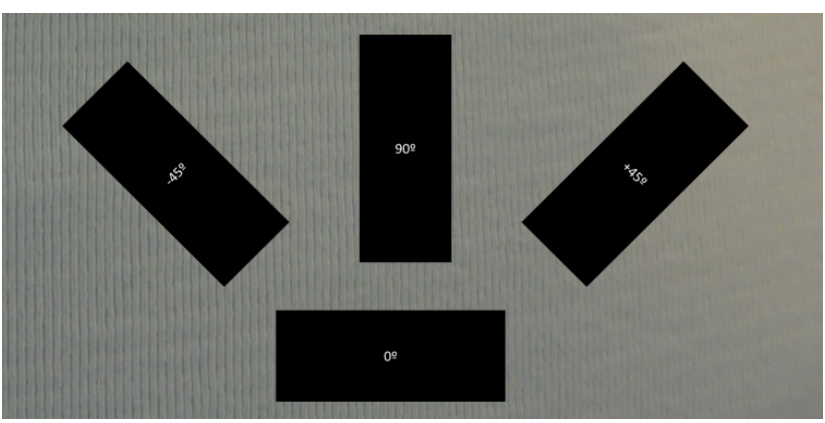

Figure 2: Schematic representation of specimens cut at different angles.

first stage (up to approximately $10 \%$ extension) during the application of a tensile load, the loops change their shape in order to accommodate the applied load. The fabric structure allows large deformation where the yarns are straightening without yarn elongation itself. At the second stage, it can be seen that the relationship between load and extension is almost linear when the fabric is stretched (from $10 \%$ up to $50 \%$ extension), where the elongation of the straightened yarn takes place. In general, from fabric samples in Figure 3, it can be seen that at the same stretching and direction (angle), the stretching force is higher for samples from Serie B than for samples from Serie A, in most of the cases. This might be due to the higher loop density of these fabrics of Serie B, the number of yarns that bear the tensile force in the samples from Serie B is more than that of the samples from Serie A (Table 1). Results also show that there are higher differences between tensile force values of samples from Serie B with different number of miss stitches. However, very little difference in tensile force values is seen between samples from Serie A with different number of miss stitches, in most of the cases. Also the tensile force is the highest when samples from Serie $\mathrm{B}$ are stretched at $90^{\circ}$ direction, the highest tensile force value is verified for the sample from Serie B with walewise compressive orientation (DOCKF_W) and with three miss stitches sequences and it is two times and half higher than that of the same compressive orientation fabrics from Serie A. The lowest tensile forces are when samples from Serie B are stretched at $0^{\circ}$ direction for fabrics with coursewise compressive orientation (DOCKF_C). When the force is applied to a fabric at $0^{\circ}$ direction the stretching force is higher for fabrics with more miss stitches (from Serie A) because they will resist stronger due to direct stretch of some polyamide yarns (without loops to deform). At $+45^{\circ}$ and $-45^{\circ}$ directions, the tensile force of samples from Serie B have higher values than Serie A, but not too much, although a small structure effect of the fabric still exists, this may be ignored as it is less important due to force orientation.

Analysing each group of samples in more detail, it is possible to observe from Figure 3a that Sample 3A from DOCKF_C group, as expected, presents the best performance at $0^{\circ}$ direction, due to the positive influence of the number of miss loops. When a knitted fabric is extended along its coursewise direction, the yarns will bear most of the force, and the higher number of miss stitches sequences (especially the ones from polyamide yarn) in this fabric might have blocked earlier the stretching, requiring higher force to stretch. In this way, Sample 3A with coursewise compressive orientation may provide more sustained compression to some target positions at $0^{\circ}$ direction, for the production of compression textiles.

From Figure 3b, it is observed that all samples from DOCKF_D group present similar tensile force (samples from Serie A as well as samples from Serie B), in all four directions. In this way, it can be concluded that the diagonal structure enables the control of fabric anisotropy. However, the maximum value of tensile force $(13,00 \mathrm{~N})$ was obtained by stretching Sample $6 \mathrm{~B}$, at $90^{\circ}$ direction, providing more sustained compression to some target positions at $90^{\circ}$ direction, for the production of compression textiles.

From Figure $3 c$, it can be observed that the maximum value of tensile force $(24,92 \mathrm{~N})$ for DOCKF_W Group was obtained by stretching the Sample $9 \mathrm{~b}$ at $90^{\circ}$ direction. This sample presents high loop density with higher number of miss stitches, providing better compression behaviour. In this way, Sample 9B with walewise compressive orientation may provide more sustained compression to some target positions at $90^{\circ}$ direction, for the production of compression textiles.

From Figure 3d, the maximum value of tensile force $(21,79 \mathrm{~N})$ for DOCKF_C $\& W$ Group was obtained by stretching Sample $12 \mathrm{~B}$ at $90^{\circ}$ direction. This behaviour can be explained by the higher loop density and number of miss stitches to resist the fabric stretching. This sample also shows very good performance at $0^{\circ}$ direction $(15,75 \mathrm{~N})$. Sample $12 \mathrm{~B}$ with both coursewise and walewise compressive orientations may

\begin{tabular}{|c|c|c|c|c|c|c|c|c|c|}
\hline \multirow[b]{2}{*}{ Samplegroups } & \multirow[b]{2}{*}{ Samples } & \multicolumn{4}{|c|}{ Serie A } & \multicolumn{4}{|c|}{ Serie B } \\
\hline & & Force $(\mathrm{N})$ at $0^{\circ}$ & $\begin{array}{c}\text { Force }(\mathrm{N}) \text { at } \\
45^{\circ}\end{array}$ & $\begin{array}{c}\text { Force }(\mathrm{N}) \text { at } \\
-45^{\circ}\end{array}$ & $\begin{array}{c}\text { Force }(\mathrm{N}) \text { at } \\
90^{\circ}\end{array}$ & Force $(\mathrm{N})$ at $0^{\circ}$ & $\begin{array}{c}\text { Force }(\mathrm{N}) \text { at } \\
45^{\circ}\end{array}$ & $\begin{array}{c}\text { Force }(\mathrm{N}) \text { at } \\
-45^{\circ}\end{array}$ & $\begin{array}{c}\text { Force }(\mathrm{N}) \text { at } \\
90^{\circ}\end{array}$ \\
\hline \multirow{3}{*}{ DOCKF_C } & 1 & $10.83( \pm 17 \%)$ & $11.15( \pm 6 \%)$ & $11.94( \pm 12 \%)$ & $9.09( \pm 29 \%)$ & $9.77( \pm 13 \%)$ & $10.30( \pm 9 \%)$ & $11.77( \pm 5 \%)$ & $13.56( \pm 6 \%)$ \\
\hline & 2 & $10.38( \pm 5 \%)$ & $10.03( \pm 14 \%)$ & $10.75( \pm 7 \%)$ & $10.17( \pm 8 \%)$ & $9.00( \pm 26 \%)$ & $10.11( \pm 7 \%)$ & $10.36( \pm 5 \%)$ & $14.89( \pm 18 \%)$ \\
\hline & 3 & $13.76( \pm 9 \%)$ & $9.22( \pm 5 \%)$ & $10.65( \pm 10 \%)$ & $9.540( \pm 9 \%)$ & $7.70( \pm 7 \%)$ & $9.22( \pm 5 \%)$ & $10.22( \pm 7 \%)$ & $13.75( \pm 14 \%)$ \\
\hline \multirow{3}{*}{ DOCKF_D } & 4 & $10.00( \pm 0 \%)$ & $9.33( \pm 6 \%)$ & $10.27( \pm 7 \%)$ & $10.33( \pm 3 \%)$ & $11.87( \pm 2 \%)$ & $11.50( \pm 4 \%)$ & $9.90( \pm 2 \%)$ & $11.07( \pm 6 \%)$ \\
\hline & 5 & $10.68( \pm 2 \%)$ & $10.17( \pm 3 \%)$ & $11.76( \pm 17 \%)$ & $8.87( \pm 1 \%)$ & $10.60( \pm 2 \%)$ & $10.53( \pm 2 \%)$ & $10.00( \pm 14 \%)$ & $11.81( \pm 21 \%)$ \\
\hline & 6 & $10.53( \pm 4 \%)$ & $9.32( \pm 6 \%)$ & $9.85( \pm 1 \%)$ & $9.50( \pm 8 \%)$ & $12.90( \pm 4 \%)$ & $11.47( \pm 2 \%)$ & $10.88( \pm 3 \%)$ & $13.00( \pm 8 \%)$ \\
\hline \multirow{3}{*}{ DOCKF_W } & 7 & $10.83( \pm 17 \%)$ & $11.15( \pm 6 \%)$ & $11.94( \pm 12 \%)$ & $9.09( \pm 29 \%)$ & $9.79( \pm 13 \%)$ & $10.30( \pm 9 \%)$ & $11.77( \pm 5 \%)$ & $13.56( \pm 6 \%)$ \\
\hline & 8 & $11.44( \pm 13 \%)$ & $10.44( \pm 17 \%)$ & $11.22( \pm 13 \%)$ & $10.44( \pm 21 \%)$ & $13.80( \pm 32 \%)$ & $11.04( \pm 6 \%)$ & $11.27( \pm 13 \%)$ & $18.66( \pm 24 \%)$ \\
\hline & 9 & $11.75( \pm 9 \%)$ & $13.40( \pm 8 \%)$ & $12.24( \pm 3 \%)$ & $9.94( \pm 6 \%)$ & $12.73( \pm 10 \%)$ & $13.33( \pm 8 \%)$ & $12.31( \pm 7 \%)$ & $24.92( \pm 7 \%)$ \\
\hline \multirow{3}{*}{ DOCKF_C\&W } & 10 & $10.00( \pm 0 \%)$ & $9.33( \pm 6 \%)$ & $10.27( \pm 7 \%)$ & $10.33( \pm 3 \%)$ & $11.87( \pm 2 \%)$ & $11.50( \pm 4 \%)$ & $9.90( \pm 2 \%)$ & $11.07( \pm 6 \%)$ \\
\hline & 11 & $10.53( \pm 1 \%)$ & $9.78( \pm 3 \%)$ & $10.43( \pm 6 \%)$ & $10.00( \pm 0 \%)$ & $14.36( \pm 5 \%)$ & $13.27( \pm 5 \%)$ & $12.64( \pm 4 \%)$ & $15.47( \pm 4 \%)$ \\
\hline & 12 & $11.39( \pm 4 \%)$ & $9.80( \pm 1 \%)$ & $10.33( \pm 3 \%)$ & $9.54( \pm 6 \%)$ & $15.75( \pm 1 \%)$ & $15.019( \pm 0 \%)$ & $14.67( \pm 2 \%)$ & $21.79( \pm 1 \%)$ \\
\hline
\end{tabular}

Table 2: Tensile test results at $50 \%$ elongataion. 

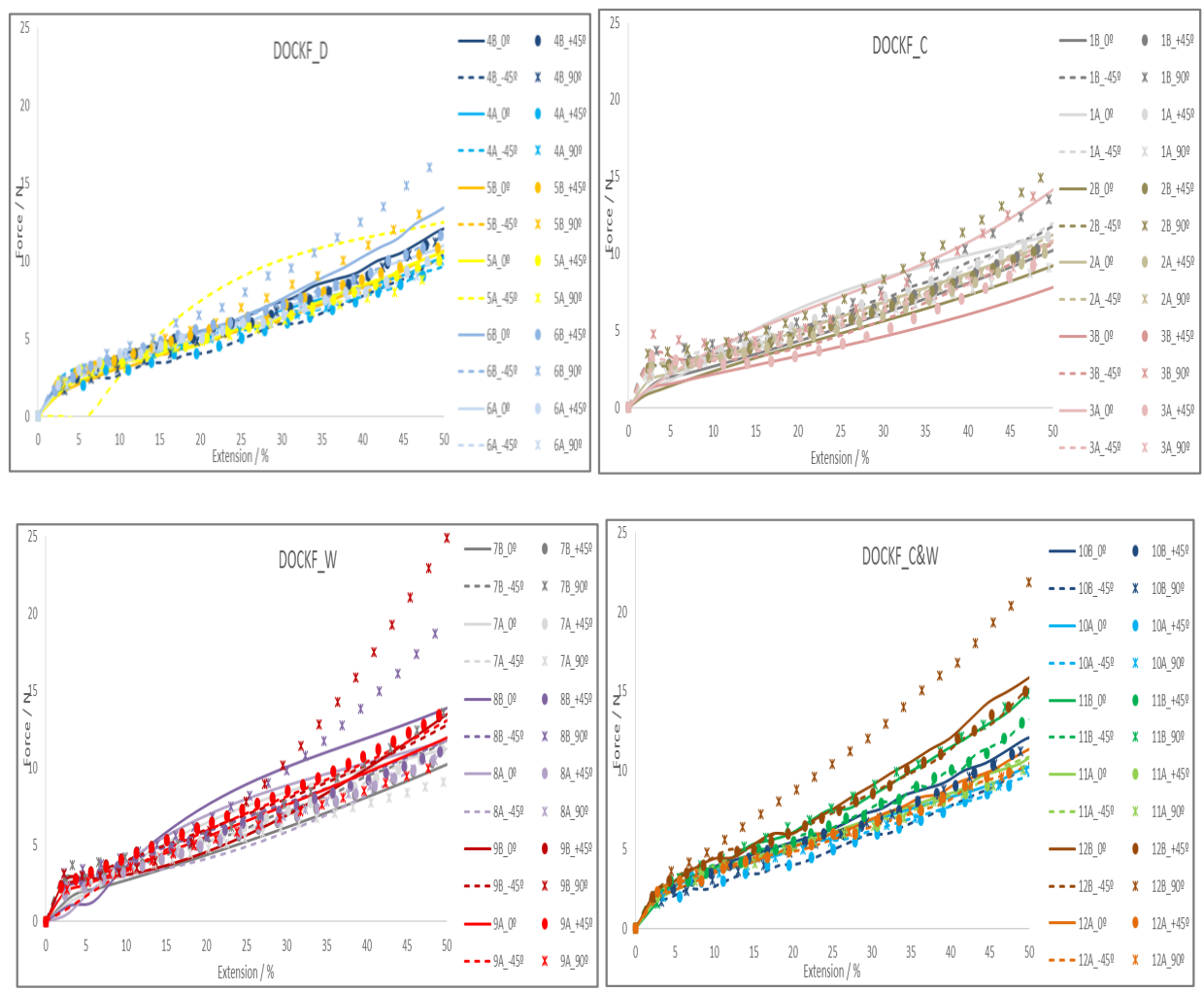

a) Coursewise orientation

b) Walewise orientation b) Diagonal orientation

d) Coursewise and walewise orientation

Figure 3: Force-extension curves of DOCKFs.

provide more sustained compression to some target positions at $90^{\circ}$ and at $0^{\circ}$ directions, for the production of compression textiles.

The results obtained showed that the developed structural designs influenced the elasticity of the knitted fabrics, and oriented compressive structures were created, furthermore a combination of knitted structures with different compressive orientations can be created, on one unique support device, to give comfortable support to different parts of the body at the same time.

\section{Influence of number of successive miss stitches $(1,2$, and 3 miss loops) on the stretch behaviour}

Figure 4a (samples from DOCKF-C Group - coursewise effect) shows the dependence of the number of successive miss loops sequences on the fabrics compressive behaviour when tested at $+45^{\circ},-45^{\circ}$ and at $0^{\circ}$, i.e. for samples represented in this figure the increase on the number of miss stitches (nms) is inversely proportional to the tensile force. This might be occurring because at $+45^{\circ}$ and $-45^{\circ}$ it is mainly the structure of the fabric that resists the stretching. The increase in the number of miss stitches leads to a decrease in the loop density of these fabrics decreasing their stretchability. The same behaviour is observed at $0^{\circ}$ for Serie $\mathrm{B}$, where only the elastane is producing miss stitches. In this case, when this fabric is extended along its coursewise direction, the yarns will support most of the force, however straight polyamide yarn (miss stitches) are not presented to block the stretching. It is possible to predict the tensile force values of designed knitted fabrics with compressive coursewise orientation when varying the number of successive miss stitches, when these fabrics are stretched along $+45^{\circ}$, $-45^{\circ}$ and courswise direction $\left(0^{\circ}\right)$. The influence of this parameter on tensile force (F) of DOCKF_C from Serie B, tested at $+45^{\circ},-45^{\circ}$ ant at $0^{\circ}$ is described by the linear equations $4.1,4.2$ and 4.3 given in Figure 4a. The influence of this parameter on tensile force (F) of DOCKF_C from Serie A tested at $+45^{\circ}$ and $-45^{\circ}$ is described by the linear equations 4.4 and 4.5 given in Figure $4 \mathrm{a}$.

For the DOCKF_D Group (diagonal effect), Figure 4b shows that the dependence of the number of successive miss loops sequences on the tensile force is only verified for fabrics from Serie B when tested at $-45^{\circ}$, i.e. for fabrics represented in this figure the increase on the number of miss stitches (nms) is inversely proportional to the tensile force. This might be occurring because at $-45^{\circ}$ it is mainly the structure of the fabric that resists the stretching; the decrease in the loop density due to the increase in the number of miss stitches, leads to less stretch resistance. It is possible to predict the tensile force values of designed knitted fabrics with compressive diagonal orientation when varying the number of successive miss stitches on the design pattern, when these fabrics are stretched along $-45^{\circ}$ direction. The influence of this parameter on tensile force (F) of DOCKF_D from Serie B, tested at $-45^{\circ}$, is described by the linear equation 4.6 given in Figure $4 \mathrm{~b}$.

Knitted fabrics of DOCKF_W group (walewise effect), represented in Figure $4 \mathrm{c}$, indicates that the increase number of successive miss loops sequences on same needles did have influence on the tensile force (F) performance of fabrics from Serie B tested at $+45^{\circ}$ and $90^{\circ}$, and of fabrics from Serie A at $0^{\circ}$. The tensile force of Serie B samples tested at $+45^{\circ}$ and at $90^{\circ}$ is correlated with the number of miss stitches (nms) sequences. The increase on the number of miss stitches is 


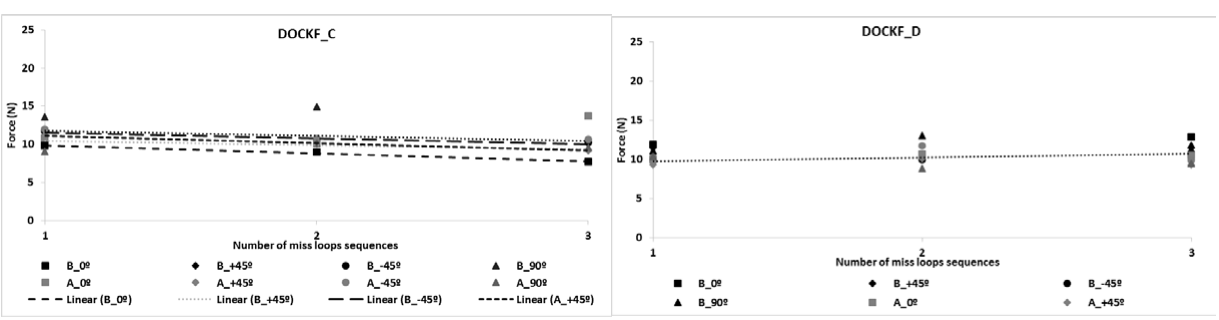

a) Coursewise orientation; Linear equations:

b) Diagonal orientation; Linear equations:

$$
\begin{aligned}
& F_{\left(B_{-}+45^{\circ}\right)}=-0,5361 \mathrm{nms}+10,948\left(R^{2}=0,8774\right) \\
& F_{\left(B_{-}-45^{\circ}\right)}=-0,7772 \mathrm{nms}+12,336\left(R^{2}=0,8188\right) \\
& F_{\left(B_{-} 0^{\circ}\right)}=-1,0431 \mathrm{nms}+10,917\left(R^{2}=0,9796\right) \\
& F_{\left(A_{-}+45^{\circ}\right)}=-0,9609 \mathrm{nms}+12,054\left(R^{2}=0,9911\right) \\
& F_{\left(A_{-}-45^{\circ}\right)}=-0,6439 \mathrm{nms}+12,401\left(R^{2}=0,8033\right)
\end{aligned}
$$$$
F_{\left(B_{-}-45^{\circ}\right)}=-0,4861 \mathrm{nms}+9,2878\left(R^{2}=0,8232\right)
$$

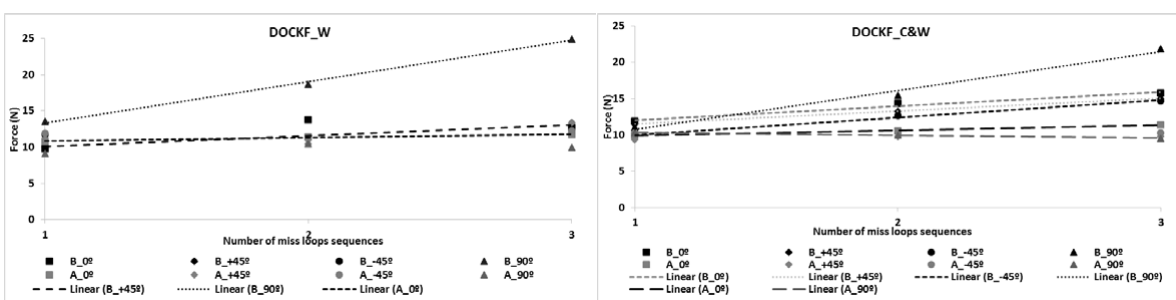

a) Walewise orientation; Linear equations

$$
\begin{aligned}
& F_{\left(B_{-}+45^{\circ}\right)}=1,5152 \mathrm{nms}+8,5252\left(R^{2}=0,9212\right) \\
& F_{\left(B_{-} 90^{\circ}\right)}=\mathbf{5 , 6 8 3 7} \mathrm{nms}+7,6813\left(R^{2}=0,9966\right) \\
& F_{\left(A_{-} 0^{\circ}\right)}=0,4604 \mathrm{nms}+10,419\left(R^{2}=0,9691\right)
\end{aligned}
$$

b) Coursewise and Walewise orientations, Linear equations:

$$
\begin{aligned}
& \mathrm{F}_{\left(\mathrm{B}_{0} 0^{\circ}\right)}=1,9397 \mathrm{nms}+10,1100\left(\mathrm{R}^{2}=0,9739\right) \\
& \mathrm{F}_{\left(\mathrm{B}_{-}-90^{\circ}\right)}=5,3609 \mathrm{nms}+5,3881\left(R^{2}=0,8188\right) \\
& \mathrm{F}_{\left(\mathrm{B}_{-}+45^{\circ}\right)}=1,7593 \mathrm{nms}+9,7432\left(\mathrm{R}^{2}=\mathbf{0 , 9 8 9 7}\right) \\
& F_{\left(B_{-}-45^{\circ}\right)}=2,3813 \mathrm{nms}+7,6410\left(R^{2}=0,9926\right) \\
& \mathrm{F}_{\left(\mathrm{A} 0^{\circ}\right)}=0,6936 \mathrm{nms}+8,2516\left(\mathrm{R}^{2}=\mathbf{0 , 9 8 1 6}\right) \\
& F_{\left(A_{-} 90^{\circ}\right)}=\mathbf{- 0 , 3 9 7 7} \mathrm{nms}+\mathbf{1 0 , 7 5 3}\left(R^{2}=\mathbf{0 , 9 9 1 3}\right)
\end{aligned}
$$

Figure 4: Force versus number of miss stitches at $50 \%$ elongation for DOCKFs.

directly proportional to the tensile force of the fabrics from Serie B, leading to an increase of the loops density which influences positively the stretch resistance. For Serie A samples tested at $0^{\circ}$ direction a good correlation has been also found. The number of miss stitches is directly proportional to the tensile force, when fabrics with compressive walewise orientation are extended along the coursewise direction, the yarns will support most of the force. The predicted tensile force of Serie $\mathrm{B}$ at $+45^{\circ}$ and at $90^{\circ}$ are given in the equations 4.7 and 4.8 respectively, and the predicted tensile force of Serie $\mathrm{A}$ at $+0^{\circ}$ is given in the equations 4.9 (Figure 4c).

For DOCKF_C\&W Group (combination of coursewise and walewise effects), Figure $4 \mathrm{~d}$ shows that the increase number of successive miss loops sequences did affect the tensile force (F) of the fabrics from Serie A when tested at $0^{\circ}$ and $90^{\circ}$. This behaviour demonstrates the importance of the polyamide yarn in resisting the stretching at $0^{\circ}$ and the importance of the design structure in resisting the stretch at $90^{\circ}$. The increase number of successive miss loops was directly proportional to the tensile force at $0^{\circ}$ and inversely proportional at $90^{\circ}$. The increase number of successive miss loops sequences did also affect the tensile force of the fabrics from Serie B. For these samples, when an increase in the number of successive miss loops sequences is verified, an increase in the tensile force in all directions is observed. The higher increment is noticed at $90^{\circ}$ direction, the force value increased $47 \%$ from 1 miss loop to 3 successive miss loops sequences, showing again that the design structure plays a key role on the elongation along the walewise direction. The predicted tensile force of DOCKF_C\&W at $0^{\circ}$ and at $90^{\circ}$ are given in the equations 4.10 and 4.11 respectively. The predicted tensile force of DOCKF_C\&W at all directions are given in the equations 4.12, 4.13, 4.14 and 4.14, in Figure 4d.

\section{Influence of the force direction on the stretch behaviour}

Fabric characteristics can be engineered to enhance the tensile properties only in the required orientations. The impact of different knitting designs orientations on tensile force of knitted fabrics at different angles (da) were studied and can be seen in Figure 5.

In DOCKF_C Group (coursewise orientation) the results show (Figure 5a) that only two samples, Sample 1A and Sample 2A, present good correlations. The best result represented was obtained at $-45^{\circ}$ 


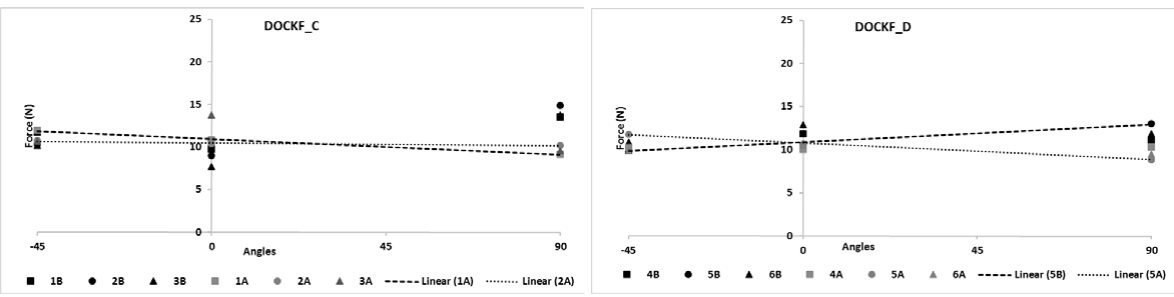

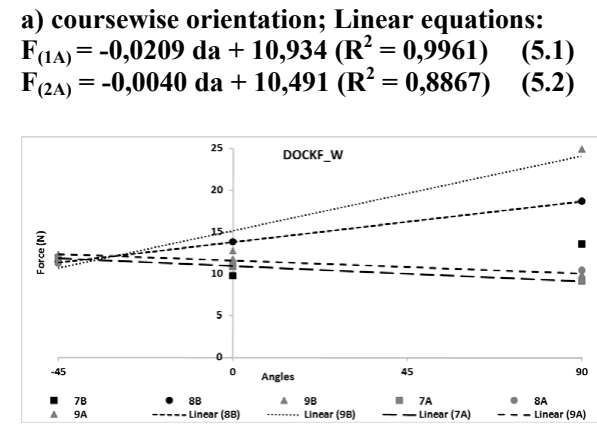

c) walewise orientation: Linear equations equations:

$\mathbf{F}_{(8 \mathrm{~B})}=\mathbf{0 , 0 5 4 7} \mathrm{da}+\mathbf{1 3 , 7 5 9}\left(\mathbf{R}^{2}=\mathbf{0 , 9 9 9 9}\right)$
$\mathbf{F}_{(\mathrm{BB})}=\mathbf{0 , 0 9 9 5} \mathrm{da}+\mathbf{1 5 , 1 6 1}\left(\mathbf{R}^{2}=\mathbf{0 , 9 1 0 2}\right)$
$\mathbf{F}_{(7 \mathrm{~A})}=\mathbf{- 0 , 0 2 0 9} \mathrm{da}+\mathbf{1 0 , 9 3 4}\left(\mathbf{R}^{2}=\mathbf{0 , 9 9 6 1}\right)$
$\left.\mathbf{F}_{(8 \mathrm{~A})}=\mathbf{- 0 , 0 1 7 5} \mathrm{da}+\mathbf{1 1 , 7}\right)$

Figure 5: Force for the different angles $\left(0^{\circ},+45^{\circ},-45^{\circ}\right.$, and $\left.90^{\circ}\right)$ for DOCKFs. b) diagonal orientation; Linear equations: $F_{(5 B)}=0,0290 \mathrm{da}+10,857\left(R^{2}=0,9961\right)$

$F_{(5 A)}=-0,0212$ da $+10,753\left(R^{2}=0,9982\right)$

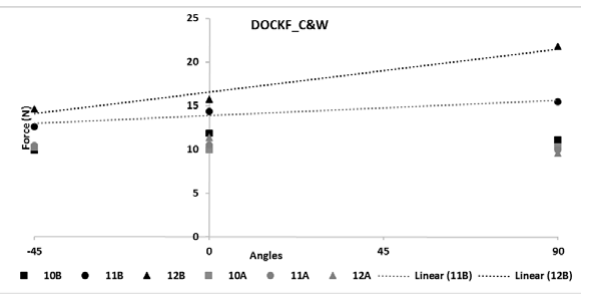

d) coursewise and walewise orientations; Linear

$F_{(11 B)}=0,0197 \mathrm{da}+13,859\left(R^{2}=0,9051\right)$

$F_{(12 B)}=0,0548 \mathrm{da}+16,579\left(R^{2}=0,9634\right)$ for both samples; the tensile force of these samples slightly increased. The force value of DOCKF_C fabrics, from Serie A with 1 and with 2 miss loops sequences, present good correlation within the different directions tested. The predicted tensile force values of DOCKF_C from Serie A are given in the equations 5.1 and 5.2 (Figure 5a). It is possible to predict the tensile force values of designed knitted fabrics with compressive coursewise orientation from Serie A, with 1 and 2 miss stitches sequences, when these fabrics are stretched along any direction.

In the group of DOCKF_D (coursewise orientation) it can be seen from Figure 5b that only two samples were representative. Represented sample 5A and sample 5B had slightly better performance at $45^{\circ}$ direction and at $90^{\circ}$ direction respectively. The tensile force of DOCKF_D samples with two miss stitches sequences and produced by Serie A and Serie B has good correlation with the different angles (da) and the predicted linear equations 5.3 and 5.4 are given in Figure $5 \mathrm{~b}$. It is possible to predict the tensile force values of designed knitted fabrics with compressive diagonal orientation from Serie A with 2 miss stitches sequences and from Serie B with 2 miss stitches sequences when these fabrics are stretched along any direction.

For DOCKF_W group (walewise effect) illustrated in Figure $5 \mathrm{c}$ the following conclusions might be drawn: for Serie B samples ( $8 \mathrm{~B}$ and $9 \mathrm{~B})$ the increase tensile force is directly proportional to the increase in the angles direction performances $\left(-45^{\circ}, 0^{\circ},+45^{\circ}\right.$ and $\left.90^{\circ}\right)$ indicating that the best performance was obtained at $90^{\circ}$ in accordance with the orientation of the structure design. As for serie A samples (7A and 8A) the increase in tensile force is inversely proportional to the increase in the angles direction performances $\left(-45^{\circ}, 0^{\circ},+45^{\circ}\right.$ and $\left.90^{\circ}\right)$ indicating that the best performance was at $-45^{\circ}$ and it is not in accordance with the orientation of the structure design. The tensile force of DOCKF_D samples with two and three miss stitches sequences from Serie B and samples with one and two miss stitches from Serie A has good correlation with the different angles and the predicted linear equations 5.5, 5.6, 5.7 and 5.8 are given in Figure 5c. It is possible to predict the tensile force values of designed knitted fabrics with compressive walewise orientation from Serie B with 1 and 2 miss stitches sequences and from Serie A with 1 and 2 miss stitches sequences when these fabrics are stretched along any direction.

From representative samples of DOCKF_C \&W group (Figure $5 \mathrm{~d})$, it can be seen that only two samples from serie B are represented, samples $11 \mathrm{~B}$ and $12 \mathrm{~B}$ have the best performance at $90^{\circ}$ direction tests, $15,47 \mathrm{~N}$ and $21,79 \mathrm{~N}$ respectively. The force value of DOCKF_C\&W fabrics from Serie B with 2 and with 3 miss loops sequences has good correlation with the different directions tested. The tensile force values of DOCKF_C\&W from Serie B are given in the equations 5.9 and 5.10 (Figure 5d). It is possible to predict the tensile force values of designed knitted fabrics with both compressive coursewise and walewise orientation from Serie B with 2 and with 3 miss stitches sequences when these fabrics are stretched along any direction.

The relationships presented in Figures 4 and 5 allows to predict the level of compression required, and design gradual and oriented compression garments by selecting the fabric structure with the right number of miss stitches and right fabric compressive orientation.

\section{Conclusions}

In this study, the influence of different structural designs on the elastic behaviour of seamless knitted fabrics composed of elastane and polyamide yarns were thoroughly investigated and discussed. Furthermore, the possibility to design knitted fabrics with directionally oriented compressive knitted fabrics (DOCKFs) was also studied. 
Citation: Cruz J, Sampaio S, Fangueiro R (2016) Development of Directionally Oriented Compressive Weft Knitted Fabrics. J Textile Sci Eng 6: 247. doi:10.4172/2165-8064.1000247

Different knitting designs with coursewise (DOCKF_C), diagonal (DOCKF_D), walewise (DOCKF_W), and with both coursewise and walewise (DOCKF_C\&W) compressive orientations were created and analysed at four different angles $\left(0^{\circ},+45^{\circ},-45^{\circ}\right.$ and $\left.90^{\circ}\right)$ and up to $50 \%$ elongation. The impact of the knitting yarn and stitch type on the stretch behaviour of DOCKFs was noticed for all the samples from DOCKF_C group, from DOCKF-D group, from DOCKF_W group and from DOCKF_C\&W group. It was found that in general, fabric constructions where only the elastane was producing miss stitches (Serie B) have higher tensile force values than fabrics from Serie A, when stretched at $-45^{\circ}$, at $+45^{\circ}$ and at walewise direction $\left(90^{\circ}\right)$. The loop density of the DOCKFs samples, was affected mainly by the type of stitch produced, and it played an important role in the tensile force values of the samples. There were higher differences between tensile force values of samples from Serie B with the different number of miss stitches, however, very little difference in tensile force values was seen between samples from Serie A with the different number of miss stitches, in most of the cases. The prediction of force values in relation to the number of miss stitches sequences and in relation to the different angles studied are made using regression model. A combination of knitted structures with different compressive orientations can be created, on one unique support device, to give comfortable support to different parts of the body at the same time.

\section{Acknowledgments}

This work is financed by FEDER funds through the Competitivity Factors Operational Programme - COMPETE and by national funds through FCT Foundation for Science and Technology within the scope of the project POCI-010145-FEDER-007136.

\section{References}

1. Cruz J, Fangueiro R, Soutinho F, Ferreira C, Andrade P, et al. (2010) Study on the Compressive Behaviour of Functional Knitted Fabrics Using Elastomeric Materials. Autex 2010 World Textile Conference, Vilnius, Lithuania.

2. Cruz J, Carvalho R, Sohel R, Fangueiro R, Coutinho G, et al. (2012) Influence of Structural and Process Parameters on Mechanical Behaviour of Elastane Yarns. The $41^{\text {th }}$ Textile Research Symposium, Universidade do Minho Guimarães, Portugal.

3. Atiyeh BS, El Khatib AM, Dibo SA (2013) Pressure garment therapy (PGT) of burn scars: evidence-based efficacy. Ann Burns Fire Disasters 26: 205-212.

4. Wang L, Felder M, Cai J (2011) Study of properties of medical compression garment fabrics. Journal of Fibre Bioengineering and Informatics 4: 15-22.

5. Senthilkumar M, Anbumani N (2014) Dynamic Elastic Behavior of Cotton and Cotton / Spandex Knitted Fabrics. Journal of Engineered Fibers and Fabrics 9: 93-100.

6. Galluzzo G, Regan P, Strong R (2013) Seamless circular or warp knitted compression garment with targeted anatomical musculature support. Patent Application 0254971-A1, USA.

7. Anon (1990) Lycra-the fitness fiber. Textiles 19: 58-61.

8. Watkinsa P (2011) Designing with stretch fabrics. Indian Journal of Fibre and Textile Research 36: 366-379.

9. Liu R, Lao TT, Wang S (2013) Impact of Weft Laid-in Structural Knitting Design on Fabric Tension Behavior and Interfacial Pressure Performance of Circular Knits. Journal of Engineered Fibers and Fabrics 8: 96-107.

10. MacRory BM, McCraith JR and McNamara AB (1975) The Biaxial LoadExtension Properties of Plain, Weft-Knitted Fabrics - A Theoretical Analysis. Textile Research Journal 45: 746-760.

11. MacRory BM, McNamara AB (1967) Knitted Fabrics Subjected to Biaxial Stress - An Experimental Study. Textile Research Journal 37: 908-911.

12. Hong $H$, de Araújo M, Fangueiro $R$ and Ciobanu $O$ (2002) Theoretical Analysis of Load-Extension Properties of Plain Weft Knits Made from High Performance Yarns for Composite Reinforcement. Textile Research Journal 72 991-996.

13. Ališauskienè D, Mikučionienè D (2012) Influence of the Rigid Element Area on the Compression Properties of Knitted Orthopaedic Supports. Fibres and Textiles in Eastern Europe 20: 103-107.

14. Zou KH, Tuncali K, Silverman SG (2003) Correlation and Simple Linear Regression. Radiology 227: 617-628.

15. de Araújo M, Fangueiro $R$, Hong $H$ (2003) Modelling and Simulation of the Mechanical Behaviour of Weft-Knitted Fabrics for Technical Application. Autex Research Journal 3: 166-172. 